\title{
Interpretación de estereotipos anglosajones contenidos en anglicismos del cine
}

\author{
Goretti García Morales ${ }^{1}$ \\ Universidad de Las Palmas de Gran Canaria
}

\begin{abstract}
It is undeniable that English exerts a powerful influence on other modern languages. There are plenty of published studies dealing with different kinds of loanwords from English; both in technical and specialised fields, as well as in common and intimate ones. This paper focuses on the scope of cinema, as the filmic medium is a strong bearer of Anglosaxon cultural references and stereotypes, American ones in particular. After having analysed a corpus of film reviews, a collection of anglicisms used in Spanish with no assimilation of any kind has been recorded. These words or groups of words have been classified according to the reality they describe. Conclusions drawn refer to their characteristics and diffusion in the recipient language.
\end{abstract}

Keywords: Anglicisms, film reviews, cultural references, anglosaxon stereotypes, hollywood influence, interpretation

\section{RESUMEN}

La influencia que la lengua inglesa ejerce sobre las demás lenguas modernas es incontestable. Numerosos son los estudios que analizan distintos tipos de anglicismos en todos los ámbitos, desde los más técnicos y jergales hasta los más ordinarios e íntimos. Este artículo se centra en el mundo del cine en cuanto que constituye un vehículo de referencias

1 Corresponding author - Departamento de Filología Moderna, calle Pérez del Toro, 135004, Las Palmas de Gran Canaria, Spain.

Email: goretti.garcia@ulpgc.es 
culturales y estereotipos anglosajones, en su mayoría estadounidenses. Partiendo del estudio de un corpus de críticas cinematográficas, se han extraído los préstamos del inglés que se emplean en español sin ningún tipo de asimilación. Estas lexías se han agrupado en función de la realidad a la que se refieren y se han extraído conclusiones acerca de sus características y difusión en la lengua receptora.

Palabras clave: Anglicismos, críticas cinematográficas, referencias culturales, estereotipos anglosajones, influencia de Hollywood, interpretación

\section{Introducción}

Una de las actividades de ocio más extendidas en el mundo desarrollado es la cinematografía. Considerado el Séptimo Arte, el cine tiene una incuestionable vertiente artística. De ahí que surjan corrientes distintas y que los grandes cineastas pasen a la historia y se consagren como grandes maestros del relato artístico. Sin embargo, su difusión masiva y el interés que despierta entre todo tipo de personas revelan que su extensión es mucho mayor que la de otras artes. En efecto, el cine es tan influyente que se ha convertido además en una industria que genera mucho dinero y expectativas. Por ese motivo, en un monográfico dedicado al rastro del inglés en el ocio, tiempo libre y entretenimiento, no podía faltar un artículo dedicado al anglicismo en el ámbito fílmico.

Es bien sabido que, por razones históricas, España cuenta con una gran tradición de doblaje y los profesionales de esta técnica gozan de un merecido prestigio. Asimismo, el subtitulado y la audiodescripción son campos cada vez más desarrollados para distintos fines. Estas disciplinas tienen que ver con el cine traducido y, en su aspecto técnico, generan gran cantidad de anglicismos, pero para rastrear la huella profunda que lo anglosajón ha dejado y sigue dejando en el español empleado en el cine, es necesario recurrir a los documentos donde se habla sobre esta materia, es decir, a las críticas y reseñas. En ellas, no solo se abordan cuestiones técnicas, sino que también se habla de géneros, actores, directores, tendencias, etc. Por otro lado, el medio escrito favorece el empleo de extranjerismos mientras que el registro oral tiende a evitarlos, como refleja muy bien el empleo de la palabra "film" o "filme", muy frecuente en textos escritos y casi siempre sustituida por "película" en la conversación (García, 2009). Es por eso por lo que estos documentos son la fuente que mejor refleja el uso real del léxico en un sentido amplio.

Desde que el anglicismo empezó a ser objeto de estudio, se apuntó al cine como caldo de cultivo de términos extranjeros, en concreto del inglés, dada la preeminencia de Hollywood en este campo. Los préstamos del inglés se instalan en 
la lengua española llegando a desplazar equivalentes léxicos patrimoniales, atribuir significados nuevos a significantes ya existentes o a generar híbridos compuestos por raíces extranjeras y sufijos españoles. El estudio de estos y otros aspectos relativos al grado de asimilación en la lengua de llegada ha generado distintas nociones y tipologías de lo que se considera préstamo. Dentro de ellas, los considerados xenismos designan una realidad propia de una cultura extranjera, si bien el uso de dicho término resulta a veces controvertido por las connotaciones extralingüísticas de falta de adaptación a la cultura meta que acarrea. J. Gómez (2005, p. 30) los compara con los inmigrantes que a toda costa mantienen los rasgos culturales de su país de origen sin integrarse en la sociedad receptora. Además cita a otros autores que consideran shérif, en su variante asimilada, un ejemplo de xenismo dado que no niega su condición de préstamo. Sin embargo, J. Gómez recomienda que se emplee la palabra extranjerismo para casos de préstamos no asimilados y se reserve xenismo para "situaciones de contacto interlingüístico donde resulte apropiado" (ibídem). Dado que en este artículo pretendemos abordar la cuestión de si los anglicismos que se emplean sin asimilar en español en el ámbito del cine se han integrado en la cultura receptora, seguiremos esta recomendación y les denominaremos extranjerismos o préstamos no asimilados. Asimismo, tomaremos como referencia la definición de préstamo cultural de Bloomfield, que "caracteriza el préstamo cultural desde una perspectiva etnológica y onomasiológica (suelen ser préstamos de "palabras" y "cosas" a la vez): "los préstamos culturales nos muestran lo que una nación ha proporcionado y enseñado a otra (...) El préstamo cultural es mutuo, se da entre lenguas con un estatus relativamente similar y se restringe a términos técnicos y novedades culturales" ( Ortega, 2011, p. 237). Sin embargo, debido a la innegable superioridad cultural estadounidense en el ámbito que nos ocupa, también tendremos en cuenta las características que este mismo autor atribuye al préstamo íntimo: "Este préstamo es unidireccional, ya que existe una lengua superior de la que parten numerosos préstamos hacia la lengua inferior" (Gómez, 2004, pp. 17-18).

Pero la influencia anglosajona en el ámbito cinematográfico, lejos de ceñirse al uso esporádico de palabras en inglés, permea también en la cultura española, lo cual se ha puesto de manifiesto con frecuencia y de distintas maneras, que van desde los lamentos de R. J. Alfaro en el lejano 1948 (p. 110), por el hecho de que "se llama villano al actor que hace papeles de malvado, musical a la zarzuela, ingenua a una dama joven, héroe al galán, cartón animado a la cinta cómica no fotografiada sino dibujada" hasta el sarcasmo de F. Lázaro ante un impacto cultural innegable:

Viendo cine [...] me cercioro de cuán educativo es y de cuánta urbanidad puede enseñarnos. Ya hace años apologicé lo estimulante que ha de 
resultar para un abaleado a punto de espicharla, que alguien se acerque a él susurrándole: «¿Te encuentras bien?» (mejor: «iTe encuentras bien, cariño?»), frente a nuestro seco y depresivo «¿Te encuentras mal?», «iTe duele mucho?», y cosas igual de imprudentes. [...] Compárese el austero «¿Qué desea?» de dependientes, oficinistas, ordenanzas y demás gente hispana, con el gentil «¿Puedo hacer algo por usted?» de filmes y filmetes (Lázaro, 2003, pp. 85-86).

J. Riquelme (1998: 59) alertaba de que la sombra estadounidense llegaba a cernirse sobre gestos, desfasados actualmente, como "los silbidos de admiración a las mujeres (difundidos por las películas de USA) en lugar de nuestros piropos, mucho más originales"; por su parte, E. Lorenzo (1996, p. 174) habla de otros gestos más intemporales: "pulgar e índice formando un círculo, pulgar hacia abajo, pulgar hacia arriba, índice y corazón formando $V$, etc.". Otro aspecto de la industria cinematográfica teñido de cultura anglosajona es el de medir las pantallas y los fotogramas en pulgadas, que, según el $D L E$, es "medida inglesa que equivale a 25,4 mm". Asimismo, trabajos como el de J. Gómez (2001) o muchos "dardos" de F. Lázaro Carreter (1997 y 2003) tratan exclusivamente de la influencia pragmática que el cine ejerce sobre nuestra lengua. En efecto, en el citado estudio, J. Gómez Capuz (2001, p. 9) afirma que este doble papel de la lengua y cultura anglosajonas, como exportadora y lengua de interferencia por un lado, y como mediadora y punto de referencia cultural por otro, se ve con bastante claridad en el mundo del cine. Ya en este siglo hemos visto cómo un cineasta - José Luis Borau - ocupaba un sillón de la Real Academia Española de la Lengua y dedicaba precisamente a este asunto su discurso inaugural titulado El cine en nuestro lenguaje. Estas palabras suyas reflejan bien la magnitud del impacto cultural del lenguaje del cine en la lengua española:

El fenómeno podría ser considerado intrascendente, otra jerga entre las muchas que nos acosan, si sus derivados no se hubieran aceptado, quizá con demasiada facilidad. No lo pensamos, pero cuando decimos que Fulano ha ganado un pastón - antes decíamos una fortuna- con su negocio o que Mengano le echa demasiado suspense a la vida -antes, teatro o cuento-, tiramos del capital heredado de Hawks y Hitchcock (Borau, 2008, p. 27).

\section{Objetivo}

El propósito de este estudio es identificar aquellos anglicismos del cine, empleados en español sin ningún tipo de adaptación, que, además de exportar un significante y un significado, traen consigo una referencia cultural o concepto propios del mundo anglosajón. Asimismo, se agruparán estas lexías en función de la realidad a la que se refieran y se extraerán conclusiones acerca de sus características. 


\section{Metodología}

Partiendo de un corpus de 405 anglicismos cinematográficos empleados en revistas sobre cine recopilado anteriormente (García-Morales, 2016), nos centramos en los préstamos puros no asimilados que han exportado también un referente cultural. Las muestras analizadas pertenecen a tres tipos de fuentes clasificadas según su grado de especialización: divulgativas (La luna de Metrópoli, suplemento del diario El Mundo; y la sección de cine de los viernes del diario El País); semiespecializadas, entendiendo por tales aquellas revistas que van dirigidas a un público interesado en el cine, pero no necesariamente experto en la materia (Dirigido Por... y Fotogramas); y especializado (Academia Revista del Cine Español y Nosferatu, ambas revistas redactadas por y dirigidas a especialistas del ámbito). De cada una de estas publicaciones se extrajeron 100 muestras de variada extensión, correspondiendo a secciones 0 artículos completos de varias páginas, todas publicadas en España en la primera década del siglo XXI. A este primer grupo, añadimos algunas otras lexías que se habían recogido en otros estudios (Bradley \& Carrera de la Red, 2004; Luján García, 2012) y que no aparecieron en nuestro corpus.

Este estudio no incluye, por tanto, los casos de préstamos asimilados en mayor o menor grado ni los calcos léxicos y semánticos, aun cuando estos pueden emplearse para expresar realidades típicamente anglosajonas, como ocurre con BAFTA, NC17 o Globo de Oro. Asimismo, dentro del grupo de préstamos no asimilados dejamos fuera todos aquellos que no remitín a una realidad propiamente americana, como los tecnicismos, que abundan en este ámbito (call sheet, front loading, chroma key, etc.); y los que, no siendo lexías técnicas, se emplean en lugar de sus equivalentes españoles (film, happy end, set, etc.).

Como es habitual en los estudios de contacto entre lenguas, existen ejemplos de dudosa naturaleza: ¿lexías como Director's cut o Snuff movie pueden considerarse vehiculares de una realidad original anglosajona?; ¿términos de uso común como bluff o freak tienen un significado específico cuando se usan en Hollywood? En el análisis de cada anglicismo daremos razón de los casos incluidos en esta nómina de préstamos culturales. $Y$ en aquellos en los que no hemos podido establecer claramente su origen o su condición de estereotipo anglosajón, hemos optado por dejarlos fuera.

Una vez seleccionados los anglicismos que habían exportado significante y referente, los agrupamos según la realidad objetiva que designaban, lo que dio lugar a las siguientes categorías:

1. Anglicismos referidos a géneros cinematográficos o a elementos que los 
componen.

2. Anglicismos referidos a tipos de personajes.

3. Anglicismos referidos a premios o certámenes.

4. Anglicismos referidos a la explotación comercial del cine.

5. Anglicismos referidos a movimientos cinematográficos.

Como queda dicho, esta clasificación solo reúne los préstamos del inglés que, a nuestro juicio, han traído consigo una novedad, no solo lingüística, sino también cultural. Muchos son los vocablos propios del cine que se emplean en inglés, como trailer, flashback o casting que no se han incluido aquí, a pesar de la frecuencia con que se usan y de que han aparecido repetidas veces en varias de las fuentes analizadas. Tampoco se hace referencia a formas asimiladas o híbridos de estos mismos préstamos puesto que han perdido parcial o totalmente su condición de extranjerismo.

\section{Relación y análisis de anglicismos del cine como vehículo de estere- otipos anglosajones}

El número total de lexías seleccionadas según el criterio señalado asciende a 68. Las detallaremos y trataremos de explicar los motivos que nos han llevado a incluirlas en este grupo de préstamos vehiculares de una referencia cultural o estereotipo anglosajón. Dado que se trata de préstamos sin asimilar, consideramos innecesario añadir una fuente que acredite su condición de anglicismo. No obstante, por distintos motivos, son frecuentes las referencias a diccionarios y glosarios en las que se recogen. Conviene señalar también que la acepción que recogemos en esta nómina es la relativa al cine, lo cual no obsta para que haya lexías con un significado adicional, no recogido aquí.

4.1. Anglicismos referidos a géneros cinematográficos o a elementos que los componen

Biopic: película basada en una biografía. El término proviene de la combinación de las dos primeras sílabas de biographical pictures y, según el Merriam-Webster, se emplea en inglés desde 1947. El Cine (2002, p.184) destaca que, aunque hay antecedentes de este tipo de cintas en filmografías francesas, húngaras y rusas, "los célebres biopics surgieron de los grandes estudios de Hollywood". Se aprecia, pues, la influencia estadounidense en el ámbito cinematográfico, más allá de la mera nomenclatura de géneros o avances tecnológicos. 
Buddy movie: El Cine (2002, p. 189) explica que este término es el que se usa en Hollywood para designar a "aquellos largometrajes en los que el protagonismo recae sobre dos o más protagonistas".

Cartoon: película de dibujos animados. M. Görlach (2001, p. 50) afirma que, en su acepción cinematográfica se prefiere - opinión que también avala E. Lorenzo (1996, p. 150) - dibujos animados. En cuanto a su inclusión en esta lista de anglicismos con carga cultural, hay que aclarar que el cine de animación nace en Francia de la mano de Émile Reynaud a finales del siglo XIX (El Cine, 2002, p. 192). Sin embargo, dado que el maestro indiscutible del cartoon es Walt Disney, pensamos que el fenómeno tal como lo conocemos hoy, es de origen hollywoodiense.

Courtroom drama: obra de ficción dramática acerca de litigios civiles o penales. En El Cine (2002, p. 230) se dice que "hay miles de cintas dedicadas al mundo judicial" y el $100 \%$ de los títulos que se destacan son anglosajones, la mayoría de ellos, americanos: desde los clásicos El proceso Paradine (Hitchcock), Doce hombres sin piedad (Sydney Lumet) o Vencedores y vencidos (Stanley Kramer), hasta los más modernos, basados en las novelas de John Grisham, como Tiempo de matar (Joel Schumacher). Además, se apunta que "las historias judiciales han alcanzado también una considerable popularidad gracias a la televisión, que ha explotado el tema [...] en series tan diversas como La ley de Los Ángeles, Murder One, Ally McBeal o El abogado", todas ellas producidas y con acción desarrollada en Estados Unidos. La lista de estas series televisivas no ha hecho más que aumentar en los últimos años, con títulos como Boston Legal (de 2004 a 2008), Law \& Order (de 1990 a 2010) o The Good Wife (de 2009 a 2016).

Criminal fiction: género de ficción relacionado con el mundo del delito: asesinatos, móviles, delincuentes, etc. Para constatar el gran impacto de este tipo de relato, no hay más que ojear los títulos y los años que llevan en antena las series de televisión de moda: CSI (en cualquiera de sus versiones: Miami, Las Vegas o Nueva York); EI Mentalista; The Closer; Castle; Hawaii 5.0; Criminal Minds, etc. "Los criminales más famosos del mundo y sus horrendos crímenes han despertado ese punto morboso que llevamos dentro, y el cine también lo ha aprovechado" (El Cine, 2002, p. 189). Desde Jack el destripador hasta Hannibal Lecter muchos son los asesinos que, desde la gran pantalla, nos han hecho tener pesadillas.

Eurowestern: género que agrupa a los westerns realizados en países de Europa, y especialmente a los realizados en España sin influencia italiana. A pesar de que en el ejemplo que aporta T. Guzmán (2003: glosario 1999-2001) se equipara semánticamente con el spaghetti-western, el eurowestern no se reduce solo a este, aunque lo incluye por definición. Algunos títulos dentro de esta categoría son: Amitié 
de cow-boy (Francia - 1910); Potato Fritz (Alemania - 1976) o Delioĝlan (Turquía 1976). Estas películas muestran la gran diversidad de países que, bien mediante la literatura, bien mediante el cine, se dedicaron a este género. Si bien este dato pudiera indicar que el eurowestern no refleja una realidad típicamente estadounidense, sino precisamente europea, consideramos que, en cierto sentido, este es un ejemplo de apropiación cultural plena: se ha tomado un género típicamente americano para adaptarlo a Europa. Se trata de cine hollywoodiense a la europea.

Far West: región de Estados Unidos situada al oeste de las Montañas Rocosas que en su día constituyó una importante zona de colonización, y, por extensión, género cinematográfico especializado en temas del Oeste (Rodríguez \& Lillo, 1997, p. 206). E. Lorenzo (1996, p. 42) recuerda que "desde Nueva York se concibe el resto del país como Midwest (Oeste Medio) o Far West (Lejano Oeste)". En efecto, este, y no el referido al género cinematográfico, es prácticamente el único uso que se da a esta lexía en inglés.

Freak: J. L. Borau (2008, p. 22) no duda en afirmar que "Friki no viene directamente del sustantivo inglés freak - monstruo o capricho de la naturaleza -, según pudiera parecer, sino indirectamente de una vieja y aterradora película de 1932, titulada Freaks". En esta película de Tod Browning la acción se desarrolla en un circo compuesto por seres anómalos debido a una malformación genética: siameses, enanos, hombres sin extremidades, etc. Lo incluimos aquí, pues, como un elemento propio de ciertas películas de terror. Actualmente, quizás estemos asistiendo a la superación de la acepción de "tarado" por la de "obsesionado rarito", gracias también a series televisivas como Big Bang Theory.

Ghost story: película de fantasmas. En el Merriam-Webster se registra el uso de esta lexía compleja en 1819. F. Rodríguez y A. Lillo (1997, p. 485), por su parte, recogen story como anglicismo empleado en español. "Desde hace unos años, los fantasmas han invadido el cine [...]. Pero el fenómeno de los fantasmas en el cine no es nada nuevo. Casi siempre han estado ahí [...] A partir de la década de 1980, Hollywood echó mano de los fantasmas para hacer comedias - los cazafantasmas, Bitelchús y Los fantasmas atacan al jefe -, cintas románticas -Always y Ghost- y cándidos entretenimientos para la infancia como Casper" (El Cine, 2002, p. 202).

Love story: película de amantes. F. Rodríguez y A. Lillo (1997, p. 322) reconocen que "el uso de esta expresión debe mucho a la popularidad que alcanzó la película del mismo nombre".

Monster mash: fórmula iniciada por la Universal por la que se acumulan espantosas 
criaturas fantásticas en una misma trama. La presencia de monstruos en el cine es tradicional. Algunos, como Frankenstein o el Hombre lobo son por todos conocidos. En los años 40, la necesidad de burlar el declive del cine de terror en tiempos de guerra hace que las productoras desempolven su muestrario de criaturas sobrenaturales y se rueden, por ejemplo, La mansión de Drácula, en la que al famoso conde le acompañan en el reparto el Hombre lobo, Frankenstein, un sabio loco y una enfermera jorobada; o La zíngara y los monstruos, que también protagonizan Frankenstein, Drácula y el Hombre lobo, los tres monstruos más conocidos de la Universal. En la actualidad, este subgénero se sostiene, entre otros, gracias a asesinos como Freddy Krueger, Jason, o Chucky y sus parientes.

Monster movie: película en la que aparecen monstruos, bichos o criaturas desagradables. Muchos monstruos famosos han nacido en cinematografías anglosajonas: "en la década de los 50, Hollywood creó algunas criaturas monstruosas para que protagonizaran cintas como El monstruo de tiempos remotos, La mujer y el monstruo o Attack of the Giant Leeches" (El Cine, 2002, p. 211).

Pulp: El Nuevo Diccionario de Anglicismos lo considera un género cinematográfico inspirado en los relatos de acción, de contenido sensacionalista violento, especialmente destinados al consumo popular. En el ejemplar $n^{\circ} 339$ de Dirigido por..., el crítico se lamenta del desconocimiento acerca de esta lexía por parte de los autores modernos. En esa recriminación queda explícito su origen anglosajón: “El término Pulp - últimamente manipulado impúdicamente por parte de algunos aficionados al cine fantástico sin cultura alguna sobre el tema que, teóricamente, dominan -, alude a las revistas de literatura "popular" - novelas del Oeste, de detectives, de terror, de ciencia ficción... - aparecidas en Estados Unidos e Inglaterra a finales del siglo XIX y que, como en el caso norteamericano, prolongaron su existencia hasta principios de los años sesenta del siglo XX".

Road movie: película cuyo hilo argumental es el viaje o la huida por carretera de los protagonistas, según el DUE. E. Lorenzo (1996, p. 375) advierte de un dato interesante: "el término road movie no aparece registrado en diccionarios recientes de inglés $(1993,1994)$. Tal vez sea un seudoanglicismo más, importado de Francia o acuñado en España". De las fuentes lexicográficas más recientes que hemos empleado (Merriam-Webster, Collins English Dictionary, Cambridge Advanced Learner's Dictionary y Gran Diccionario Oxford), solo aparece en el Collins. No deja de ser curioso que un diccionario de español (DUE) recoja un anglicismo patente y que este no forme parte indiscutible del acervo lexicográfico nativo. Se trate o no de un pseudoanglicismo, no cabe duda de que su significación unívoca está extendida en el lenguaje cinematográfico. Asimismo, cabe destacar el más que probable impacto 
que las road movies han tenido en un fenómeno extendido en España: el de querer conducir por la mítica Route 66 como una experiencia memorable.

Screwball comedy: subgénero de la comedia romántica que se basa en el enredo. En El Cine (2002: 30) se habla del éxito de estas películas, sobre todo en los años 30: "Algunos títulos reventaron las taquillas. Y es que el éxito de estas cintas dependía de una ecuación bastante simple: un director de cierta sensibilidad, más una historia de amor casi oculta por una serie de enredos cómicos, y una pareja de actores con gancho". Continúa citando obras emblemáticas de este género como Sucedió una noche, La fiera de mi niña o Historias de Filadelfia.

Space opera: El Merriam Webster lo recoge desde 1949 como "fantasía melodramática futurista que incluye viajeros espaciales y seres extraterrestres". Dentro del género de ciencia ficción, "al cine siempre le ha apasionado la idea que no estamos solos en el universo" (El Cine, 2002 188). "El gran apogeo del género se produjo en la década de 1950 [...]. Hollywood puso en marcha distintas producciones de ciencia ficción que tuvieron una extraordinaria acogida [...]. Y por supuesto no pudieron faltar los extraterrestres" (ibídem: 188). Títulos tan emblemáticos como E.T. o La Guerra de Las Galaxias nos remiten directamente al imperio fílmico por excelencia. También se observa una clara injerencia de este género en la cultura en frases de uso corriente, como "que la fuerza te acompañe" o "mi casa, teléfono".

Slapstick: comedia basada en las payasadas y las tomaduras de pelo. T. Guzmán (2003, glosarios combinados) explica el origen de la lexía: "recibe el nombre de un objeto que empleaban los payasos en el circo - dos tablas que, al golpearlas contra la espalda de alguien, sonaban mucho". En efecto, en el Merriam-Webster, que data la primera aparición de la palabra en 1896, se contempla este artilugio de madera como primera acepción y, como segunda, la comedia. El origen del género puede haberse dado en Europa, pero los grandes maestros del Slapstick trabajaron en la meca del cine: Charles Chaplin, Buster Keaton, Stan Laurel, Oliver Hardy, Fatty "Roscoe" Arbuckle e incluso los hermanos Marx.

Slasher: subgénero del cine de terror, en el que destaca la presencia de un brutal asesino y que se desarrolla en un ambiente sórdido. Películas emblemáticas de este género son La matanza de Texas o Viernes 13, que han dado lugar a personajes explotados en distintas películas [V. Monster mash]

Splatter: película o ficción caracterizada por escenas en las que hay derramamiento de sangre. M. Görlach (2001: 299) lo recoge, pero no registra su uso en español. No obstante, tanto en nuestro corpus como en el de C. Luján (2012), aparece. En el Merriam-Webster se data en 1980 un uso adjetivo, cuya única acepción es la 
relacionada con el cine. En la Enciclopedia Universal Multimedia Micronet, se da una variante española para esta voz: "Las principales corrientes del cine de horror moderno pasan por el gore o splatter, una vertiente sangrienta y exagerada, denominada también terror explícito".

Spaghetti Western: película europea del Oeste, especialmente la realizada por un director italiano. El Merriam-Webster la registra en inglés desde 1969, poco después de que, según El Cine (2002, p. 225), se creara el género con los primeros westerns de Sergio Leone: "a comienzos de los años 1960 nació el denominado 'spaghettiwestern', un subgénero en principio masacrado por la crítica especializada, pero que, enseguida, contó con una legión de seguidores. Italia y España, que aportó los paisajes de Almería como escenario para este tipo de cintas, encabezaron la producción de westerns europeos en la que, ocasionalmente, también participaron Alemania y Francia. [V. Eurowestern]

Swashbuckling: películas de capa y espada. Si bien el DLE recoge la lexía compleja "comedia de capa y espada", referida a un género teatral del siglo XVII en el que intervenían caballeros, en El Cine (2002, p. 197) se explica que "dentro del cine de aventuras existe un subgénero conocido con el nombre de 'capa y espada'. Este agrupa producciones de época protagonizadas por un héroe romántico que defiende sus ideales manejando con gran habilidad la espada". Según esta fuente, el paradigma de estas producciones lo representa Errol Flynn.

Sword \& Sorcery: fantasía heroica o épica. Originalmente es un género literario, pero en lo relativo a la gran pantalla, se dice en El Cine (2002, p. 201) que, "en la década de 1980, la fantasía oriental se vio sustituida por otra variante denominada 'fantasía heroica', precedida por el éxito que habían alcanzado las llamadas novelas de 'espada y brujería"', que es la traducción literal de sword and sorcery. Se trata, pues, al igual que pulp, de un término que inicialmente pertenecía al ámbito literario y que acaba dotado de un significado cinematográfico al adaptarse a este medio o emplearse en él.

Techno-thriller: Aparece definida desde 1986 en el Merriam-Webster como thriller cuya trama se apoya en la tecnología moderna. De su especial relación con el cine de Hollywood dan cuenta tanto el origen del thriller a secas, como el hecho de que en Estados Unidos se produjo el gran auge de los efectos especiales aplicados al cine.

Teenexploitation: a pesar de que las películas de adolescentes constituyen un verdadero género, lo abordaremos dentro de los anglicismos relacionados con la explotación comercial del cine.

Thriller: obra cinematográfica o literaria que suscita expectación ansiosa por conocer 
el desenlace. M. Görlach (2001, p. 321) observa que, a pesar de las dificultades fonéticas que presenta la pronunciación $/ \theta r-/$, es un anglicismo conocido universalmente, lo que atribuye sin duda al empleo frecuente del término para referirse a las películas. En este sentido, E. Lorenzo (1996, p. 447) asegura que "ha habido propuestas de adaptar thriller al castellano sin que ninguna haya triunfado". Quizás por este motivo no se recoge en el $D L E$, y el $D P D(2005$, p. 634) recomienda que se sustituya por suspense, "a pesar de su extensión en el uso". Sin embargo, J. L. Borau (2008, p. 18) asegura que esta es una equivalencia errónea, pues "no es lo mismo thriller que película de suspense". En El Cine (2002, p. 229) se habla del origen, esta vez británico, del término y de su introducción en el español: "Durante mucho tiempo hubo un tipo de películas que pertenecían al género de suspense o intriga. Después, llegó de los países anglosajones un nuevo término que no tardamos en adoptar, el thriller, que sin embargo dio lugar a una confusión considerable. Porque, ¿qué es en realidad un thriller? A la vista del uso que hacen ciertos especialistas de este término, no resulta fácil definirlo como género. Y es que se han calificado como thriller obras policíacas, de espionaje o de terror. La palabra thriller nació en Gran Bretaña, y se empleó para calificar a ciertas obras literarias - y más tarde cinematográficas - que pretendían generar tensión y suspense entre el público".

True story: película basada en hechos y personajes reales. En el All Movies Guide Film Glossary, que es una de las fuentes que emplea T. Guzmán (2003) en su estudio sobre el impacto de anglicismos léxicos en revistas de cine, aparece True Story y se pone como ejemplo la película The Right Stuff (Estados Unidos, 1983), titulada en español Elegidos para la gloria, en la que se cuenta la historia de los inicios de la carrera espacial, incluyendo las circunstancias personales de los astronautas, sus entrenamientos, sus viajes y sus problemas familiares.

Western: género de películas que transcurren en el oeste de Estados Unidos en tiempos de guerra con los indios americanos o en las que aparecen personajes como los cowboys, el sheriff, etc. El Cine (2002, p. 232) sentencia que "todos los especialistas están de acuerdo en que la década de 1950 fue la edad de oro del western norteamericano" y añade que "se puede decir que en la década de 1970 el western dejó de existir como tal, puesto que ya no se dio una producción de películas continuadas adscritas a este estilo". Sin embargo, el DLE incluye este anglicismo sin asimilar por primera vez en la edición de 2001.

Women's Picture: T. Guzmán define este término como películas que tratan temas relacionados con las mujeres, incluidos deseos, sueños, retos, problemas y males sociales, desde la perspectiva de una mujer adulta. La autora aporta esta definición adaptándola del equivalente women's film, que recoge All Movies Guide Film Glossary. 
En esta fuente se añade que la etiqueta de women's film normalmente la cuelgan escritores varones a películas que van desde los romances hasta los culebrones y que, en la década de los 70, se produce un cambio en estos estereotipos femeninos. Entre los ejemplos de películas acerca de mujeres o de su interés, destaca: Mildred Pierce (1945); Madame Bovary (1949); The Prime of Miss Jean Brodie (1968), que en español se tituló Los mejores años de Miss Brodie; Alice doesn't live here anymore (1974), en España, Alicia ya no vive aquí; y Love letters (1983). Todos estos títulos son de factura hollywoodiense o británica.

\subsection{Anglicismos referidos a tipos de personajes}

Bondgirl: modismo que se aplica a las muy atractivas actrices que aparecen en las películas de James Bond, en papeles mayores, pero secundarios al del agente. T. Guzmán (2003, glosario 1999-2001) define bonds como “un nombre común, de James Bond, que se emplea para hacer referencia a las muchas películas que tienen al famoso agente especial creado por lan Fleming como protagonista", pero no recoge el uso en español de la lexía sin asimilar para las coprotagonistas de la saga. En un epígrafe dedicado a "mujeres de ensueño" en El Cine (2003, p. 212), se dice de Ursula Andrews que "tuvo el honor de inaugurar la galería de chicas Bond en Agente 007 contra el Dr. No". T. Guzmán (2003, glosarios combinados) afirma que "su trabajo en estas películas es a veces su primer paso hacia la fama, como fue el caso de Ursula Andrews y Raquel Welch".

Bounty killer: persona que se encarga de matar a bandidos en busca de la recompensa que se ofrece por ellos. Normalmente se aplica al protagonista de los westerns, aunque en español es más frecuente el empleo de la voz cazarrecompensas, cuya primera inclusión en el $D L E$ se da en la vigésima tercera edición.

Cowboy: EI DUE lo define como vaquero de las grandes praderas del Oeste de los Estados Unidos. Görlach (2001, p. 75) añade que se trata de una figura convencional de la tradición estadounidense y afirma que este es uno de los extranjerismos más conocidos del siglo XIX. Asimismo, muchos estudiosos del anglicismo, como Alfaro, Stone, o Bookless (Cfr. Pratt, 1980, pp. 94, 99 y 104) han dado su parecer sobre esta voz. A pesar de su solera, el DLE no lo recoge. En el DPD (2005, p. 662), se dice que vaquero "es la voz que se usa tradicionalmente en español para designar al personaje típico de las películas del Oeste, que vigila y conduce a caballo los rebaños de reses vacunas". Y se añade: "es, pues, innecesario el uso en español del término inglés cowboy". Aunque en las definiciones del término en inglés no se hace referencia al estereotipo de personaje cinematográfico, en la segunda y tercera 
acepciones de M. Görlach en A Dictionary of European Anglicisms (ibídem) queda implícito que se trata de un prototipo de personaje, americano y sin escrúpulos. Además, añade que el término nunca se aplica a los ganaderos de reses vacunas nativos, sino a las actitudes y formas consideradas típicas del Oeste Americano.

Gangster: el DLE lo define escuetamente como miembro de una banda organizada de malhechores que actúa en las grandes ciudades. Sin embargo, su relación con el cine y su reconocimiento como estereotipo estadounidense es innegable. Ch. Pratt (1980, p. 215) así lo demuestra: “El cine y la televisión [...] han acuñado voces siempre tomadas del inglés - para referirse a su contenido: duros, vampiresa, cuchillo largo, sheriff, gángster y un largo etcétera". Igualmente, en el Nuevo Diccionario de Anglicismos, F. Rodríguez y A. Lillo (1997, p. 238) observan que "se emplea a menudo en referencia al contexto norteamericano, y de manera especial a los protagonistas de las películas". En El Cine (2002, pp. 203-204) se hace un recorrido de la evolución que ha sufrido el personaje a lo largo de la historia del séptimo arte: "Estos personajes llegaron a la pantalla en 1927 de la mano de Josef von Sternberg y su magnífica cinta La ley del Hampa. Desde entonces, el gángster del cine adoptó la imagen del célebre Al Capone. [...] En la década de 1930 conocimos a los mejores gángsteres de la historia del cine [...]. Este modelo de gángster al estilo Capone se mantuvo en el cine durante décadas [...]. En 1972, el cine de gángsters vivió su más profunda transformación con el estreno de El Padrino, de Coppola. La imagen cinematográfica de los mafiosos cambió por completo [...]. En 1990, Martin Scorsese provocó una segunda revolución con Uno de los nuestros, dando paso al gángster moderno".

Greaser: según el Merriam-Webster, se usa desde 1641 para referirse a un habitante o nativo de Latinoamérica, especialmente de México, o de tierras mediterráneas. Si bien es verdad que esta voz no es específica del cine, lo cierto es que su uso actual está bastante restringido en la lengua común, y este se reserva prácticamente para definir a un tipo de personaje ficticio, tal y como aparece en esta crítica del $n^{\circ}$ 41/42 de Nosferatu: "[...] resulta lacerante certificar el racismo inherente a este tipo de producciones de origen latino, que representan el mal y la violencia ciega a través de la figura estereotipada del bandido mexicano, heredero de aquellos otros forajidos, greasers y chicanos elucubrados en los modosos despachos hollywoodienses [...]".

It-girl: mujer atractiva y joven que sale mucho en los medios de comunicación no siempre por asuntos relativos a su profesión. En el Collins English Dictionary (1991, p. 821) se recoge el pronombre it con las acepciones eufemísticas de relación sexual, sex-appeal y cualidad o habilidad deseables. Asimismo, M. Görlach (2001, p. 165) dice que las dos primeras acepciones mencionadas se han tomado prestadas en español 
desde los años 30, aunque se emplean poco, y solo en el lenguaje periodístico. Al parecer, la lexía compleja fue acuñada por el guionista Elinor Glyn, quien lo aplicó a Clara Bow, actriz protagonista de la cinta estadounidense It, estrenada en 1927 (Baker, 2001). Así pues, el término nace en el cine y se aplica actualmente a mujeres del mundo cinematográfico, aunque también se extiende a otras mujeres famosas.

Loner: personaje varón, típico del western, que evita el trato con otras personas. En la muestra de nuestro corpus (Nosferatu $n^{\circ} 41 / 42$ ) se aplica al coronel Pennbroke, personaje del spaghetti-western, Una razón para vivir y una para morir, del que se dice que es "un loner sin paz, que tras haber perdido todo (el honor, los afectos, la dignidad) persigue una venganza que se convierte en obsesión". En inglés común se usa desde 1947 (Merriam-Webster) y no se asocia directamente con el cine, pero en español no se registra su uso fuera de este ámbito.

Loser: El Nuevo Diccionario de Anglicismos lo define como perdedor sin hacer referencia al cine. Sin embargo, un crítico de Nosferatu ( $N^{\circ} 51$ ) no duda en decir que el loser es un "personaje mítico de la cultura norteamericana". En ese mismo ejemplar, en otro artículo titulado precisamente Tras la pista del loser, se aportan múltiples ejemplos de cine clásico donde la figura del perdedor es recurrente. Por otro lado, últimamente, se observa el uso de esta lexía en español coloquial entre los jóvenes, probablemente a causa de la película para adolescentes, Loser, candidata para ganar un Teen Choice Award, que fue dirigida por Amy Heckerling y se estrenó en 2001 en España con ese mismo título. Uno de los carteles promocionales muestra a un chico formando una I (de loser) con los dedos pulgar e índice de la mano izquierda. Este gesto también parece haberse extendido entre algunos adolescentes españoles, y es señal de la gran influencia anglosajona en la cultura española. En este sentido, la palabra adquiere una segunda acepción, referida al típico personaje con poco éxito, frecuente en películas de instituto estadounidenses.

Outlaw: persona fugitiva de la ley o sin ella. E. Lorenzo (1996, p. 588) registra el uso del préstamo puro en español desde los años 50, aunque reconoce que este uso es marginal y que normalmente se emplea el calco fuera de la ley. Este autor no menciona el cine como el ámbito donde se emplea, pero todos los ejemplos que aporta son cinematográficos. A ello se suma que "la recreación de personas que están fuera de la ley ha protagonizado algunos de los mejores westerns de la historia. $Y$ es que este es uno de los pocos géneros que permite justificar que algunos de sus héroes vivan al margen de la legalidad" (El Cine, 2002, p. 202).

Outsider: F. Rodríguez y A. Lillo (1997, p. 370) lo definen, entre otras acepciones, como "persona marginal o rebelde que no comparte los valores de la sociedad establecida". Aplicado al ámbito cinematográfico también se usa para designar al 
profesional que se excluye voluntariamente de un círculo profesional (en una de nuestras muestras se consideraba a Sam Peckinpah un outsider). No obstante, como personaje fílmico se refiere a una persona rebelde. Cabe recordar que la película Rebeldes, de Francis Ford Coppola, que lanzó a la fama al Brat Pack se llamó The Outsiders en versión original.

Pin-up: en inglés (Merriam-Webster) existen el adjetivo y el sustantivo pinup ("que se puede colgar" y "fotografía que se cuelga" respectivamente) y, desde 1941, la lexía compleja pinup girl para referirse a la chica que aparece en esa fotografía que se cuelga en la pared. En español, pin-up solo designa a la persona, aunque una de las acepciones se refiere exclusivamente a la "modelo fotográfica de gran atractivo dedicada especialmente al retrato erótico publicitario" (DUE, 2007, p. 2300). En todo caso, las pin-up girls tienen sus orígenes en la meca del cine: "Durante la segunda guerra mundial, Hollywood puso de moda a las pin-up, bellezas que tenían que animar a los soldados que estaban en el frente. Muchas chicas guapas pasaron por las pantallas, pero solo unas pocas causaron furor" (El Cine, 2002: 199). M. Görlach (2001, p. 233) dice que se emplea en español desde los años 60.

Psycho killer: asesino psicópata de las películas de terror. En El Cine (2002, p. 60) se dan algunas claves sobre el origen de este personaje: "el cine de terror fue posiblemente el género que experimentó mayor crecimiento desde finales de la década de 1970. [...] frente a las posesiones de todo tipo, las casas encantadas y los fenómenos paranormales, surgió una nueva pesadilla que supuso un importante cambio en el rumbo del género: el psicópata asesino [...]. Sería John Carpenter, en 1978, quien realmente inauguró el estilo «psycho-killer» con La noche de Halloween, una modesta producción de horror que sentó las bases de este subgénero".

Scream queen: actriz que se asocia con las películas de terror, ya sea por una intervención destacable en el género, o por apariciones constantes en el papel de la chica protagonista. Literalmente significa reina del grito. Una actriz reconocida universalmente como la primera scream queen es Fay Wray, que participó en películas de terror míticas como King Kong o Los crímenes del museo de cera.

Serial killer: individuo que asesina a varias personas en serie. Tanto T. Guzmán (2003) como F. Rodríguez y A. Lillo (1997, p. 449) atestiguan que, en español, es una palabra relacionada con el lenguaje cinematográfico. Comparte con psycho killer su origen hollywoodiense.

Sheriff. el DLE lo define como representante de la justicia que se encarga de cumplir la ley en los Estados Unidos de América y ciertas regiones o condados británicos. El DUE (2007, p. 2713) y M. Görlach (2001, p. 279) dejan constancia de que "las películas 
llamadas del Oeste (el Oeste de los Estados Unidos) han generalizado este término entre los españoles". Asimismo, J. L. Borau (2008, p. 18) considera que sheriff pertenece al ámbito cinematográfico y que no parece lógico sustituirla por comisario.

Vamp: como lexía sin asimilar no aparece recogida en el DLE, pero la definición de vampiresa que aparece en esta fuente, remite al ámbito fílmico: "aquella cuyo poder de atracción amorosa acarrea fin desgraciado a sí misma o a quienes atrae. Utilícese referido principalmente a personajes de ficción, sobre todo de cine, y a las actrices que los representan". EI DPD (2005, p. 662) concreta la procedencia de este personaje de ficción: las películas de cine negro. Asimismo, en El Cine (2002, p. 231) se dice que "la vampiresa o mujer fatal es un personaje propio, sobre todo, del cine negro. Su origen se encuentra en las divas del cine mudo [...], que interpretan personajes que solo con su poder de seducción manejaban la voluntad de los hombres. A partir de la década de 1940, la mujer fatal adquirió fuerza en el cine policíaco [...] A partir de 1980, la mujer fatal del cine policíaco volvió a las pantallas con una fuerza arrolladora". M. Görlach (2001, p. 340) dice que en español se empieza a usar en la década de 1970, época intermedia entre las dos de esplendor de este personaje. No obstante, según J. L. Borau (2008, p. 22), la génesis del personaje como tal se remonta a principios del siglo XX: "En 1914 la compañía norteamericana Biograph decidió producir una adaptación del poema de Rudyard Kipling 'The Vampire'. El éxito fue tal que su protagonista, Theda Bara, se vio obligada a repetir el personaje una y otra vez acabando por ser tenida como la primera vampiresa del cine".

Villain: Ch. Pratt (1980, p.169) define el calco semántico villano como malhechor. Las que se dan en el DUE (2007: 3051) y en el DLE no son tan aplicables al personaje cinematográfico. E. Lorenzo (1996, p. 559) dice que "la dicotomía adoptada por los críticos de cine ha convertido al malo y al bueno de la terminología popular en el villano y el héroe de su jerga [...]. En inglés los modelos son the villain and the hero". J. L. Borau (2008: 20), por su parte, establece una gradación: "si la catadura moral del malo rozaba la infamia, según solía ocurrir, pasaba a ser el villano por antonomasia". Asimismo, F. Lázaro Carreter (2003, p. 86) ironiza al decir que "lo de llamar villanos a los malos" es consecuencia de una indudable conspiración que tienen "contra nosotros los laboratorios de doblaje"; y que "es muy grande la aportación que al idioma puede hacerse desde el arte cinematográfico".

Zombie: personaje de película que está muerto pero que tiene capacidad de moverse por artes mágicas. Ni el DUE ni el DLE reconocen que sea anglicismo. Como etimología remiten al africano occidental. Sin embargo, E. Lorenzo (1996, p. 481) 
aclara que, aunque "sea voz criolla del Caribe o tomada del África occidental, zombi, incluida en el $D L E$, parece haberse difundido a través del inglés zombie". También lo reconoce M. Görlach (2001, p. 352), al incluirla en su Dictionary of European Anglicisms, y el DPD (2005, p. 687), al decir que es "voz de origen africano occidental, introducida en español a través del inglés". El Cine (2002, p. 233) recoge que una de las primeras cintas de zombies emblemáticas - La Momia - se rodó para la Universal en 1932 y atribuye al cineasta estadounidense, George A. Romero, la irrupción en escena de este tipo de películas. Recientemente, la televisión ha contribuido a su resurgimiento con la archiconocida serie The Walking Dead, del también estadounidense Frank Darabont.

\subsection{Anglicismos referidos a premios o certámenes}

British Independent Film Awards: premios que otorga una institución no gubernamental fundada en 1998 por varios productores, críticos y otros miembros de la comunidad cinematográfica británica. Como se lee en su página web oficial (http://www.bifa.org.uk/), nació para reconocer las películas de financiación independiente y darlas a conocer entre un público más amplio.

For your consideration: frase promocional que aparece como enunciado en algunas revistas de entretenimiento en las que se presentan películas candidatas a distintos premios cinematográficos. Va dirigida a los jurados o votantes para que consideren la candidatura. Aunque fuera del contexto cinematográfico, se emplea en inglés con significado general, la frase se relaciona de tal manera con este recurso promocional que, en 2006, dio título a una comedia sobre tres actores cuyas interpretaciones en una determinada película activan los rumores acerca de una posible candidatura al Oscar.

Oscar: El DLE recoge dos acepciones: la de premio anual concedido a los profesionales del cine por la Academia estadounidense de las Artes y Ciencias Cinematográficas; y la de estatuilla que representa este premio. A pesar de que en el uso que recogemos aquí se emplea sin tilde, no es su apariencia formal lo que mejor demuestra su carácter anglicado. Quizás sea esta una de las lexías que mejor transmiten la influencia anglosajona en el mundo del cine y en la lengua: "son los premios por excelencia del cine, conocidos hasta en el último rincón del mundo. La emisión televisiva de la gala de entrega de los premios Oscar no solo moviliza a los espectadores norteamericanos, sino a una audiencia completamente internacional" (El Cine, 2002, p. 439).

Razzie: premio paralelo al Óscar, pero otorgado a los peores trabajos y, por extensión, ceremonia en la que se hace entrega de estos premios. El galardón es 
una frambuesa de oro, de ahí el nombre de los premios (razzie es la forma coloquial para raspberry). Los premios Razzie fueron creados por el crítico y escritor de cine, John Wilson, en 1980.

Teen Choice Awards: premios con los que la cadena Fox reconoce a las estrellas favoritas de los adolescentes. Literalmente, significa "premios de elección adolescente" $y$, de hecho, los galardones se otorgan a los artistas que hayan elegido las personas entre 13 y 19 años.

\subsection{Anglicismos referidos a la explotación comercial del cine}

Blockbuster: cualquier película que causa gran impacto y tiene un enorme éxito taquillero. Aunque originariamente en inglés se empleaba como sustantivo, referido también a otros ámbitos, la primera acepción que aparece en los diccionarios actualizados es la cinematográfica $\mathrm{y}$, exceptuando el significado de bomba de demolición, no parece emplearse ya, salvo en el caso de los éxitos fílmicos o literarios. F. Rodríguez y A. Lillo (1997, p. 75) sitúan su origen en block ('bloque') y buster ('lo que revienta').

Box office: ingresos obtenidos de la venta de entradas. M. Görlach (2001, p. 34) apunta que en español es muy poco frecuente y adscribe su uso al lenguaje técnico y al periodístico.

Davie-Brown Index: informe estadounidense que mide la capacidad de las estrellas para vender productos. Aunque el Davie-Brown Index no aporta datos solo de estrellas cinematográficas, lo cierto es que en los puestos más altos del informe, que se actualiza semanalmente, suelen aparecer actores.

Director's cut: versión de una película editada según los deseos del director y que suele incluir escenas que se han suprimido en la versión de la cinta para la distribución general. El autor de El Cine (2002, p. 100) ve en el director's cut una estrategia de marketing: "En los últimos años se ha puesto muy de moda presentar 'el montaje del director' o director's cut de una producción de éxito que ya se ha estrenado. Estos reestrenos cuentan con planos que no fueron incluidos en el montaje original, e incluso pueden tener un final diferente al conocido por el espectador. En algunos casos, son interesantes; en otros, no se trata más que de prolongar gratuitamente el metraje de la película con unos cuantos planos nuevos y, de esta manera, tener la posibilidad de explotar comercialmente de nuevo la cinta". De la novedad de esta práctica dan cuenta el Merriam-Webster al registrar el primer uso de esta lexía en 1980; y el hecho de que solo recoja el empleo de esta lexía en español T. Guzmán, en el glosario de 1999-2001. 
Indie: compañía cinematográfica independiente y películas producidas por ella. El término "indie" se emplea muchas veces en oposición a "mainstream" y a "major".

Mainstream: cualquier película comercial, que sigue las líneas convencionales. F. Rodríguez y A. Lillo (1997, p. 327) lo engloban en la cinematografía y dejan constancia de que "en inglés el término tiene una referencia más general". En efecto, en el Merriam-Webster se define como "corriente predominante o tendencia de una actividad o influencia" y se registra su uso desde 1599. M. Görlach (2001, p. 193), por su parte, sitúa su empleo original en los aficionados a la música popular y apunta a una moda entre los intelectuales como causante de su difusión más general.

Major: gran compañía cinematográfica o discográfica. En inglés también se emplea en su forma sustantiva para designar cualquier ente o actividad "superior en rango, importancia, tamaño o actuación" desde 1616 (Merriam-Webster), pero, usado en el ámbito cinematográfico, se refiere, sin necesidad de aclaración, a los grandes estudios de cine norteamericanos (Metro-Goldwin-Mayer, 20th Century Fox, Warner...), que dominan la industria del cine mundial. De este sistema no hemos importado solo esta lexía, sino algunas prácticas comerciales: "Las majors, como se las conoce ahora, dominan la distribución mundial [...] realizan un tipo de estrategias difícil de seguir. Para empezar, han trasladado de Estados Unidos la tradición de estrenar en viernes, cuando antes se hacía los lunes. De igual forma han impuesto la costumbre de medir el éxito de una película por lo que esta recauda en su primer fin de semana" (El Cine, 2002, p. 160).

Making of: reportaje en el que se explica cómo se ha grabado una película ( $F$. Rodríguez-A. Lillo). En inglés, como explican F. Rodríguez y A. Lillo (1997, p. 328) no ha lexicalizado como término, sino que "se emplean expresiones descriptivas como the film behind the film, the film about the film, documentary, etc". Sin embargo, cualquier hablante nativo comprende qué significa making of, ya sea de una película o de cualquier otro objeto (literalmente, la creación de). En El Cine (2002, p. 134) se lee: “El interés del público por saber cómo se hacen las películas ha llegado a tal punto que, desde hace unos cuantos años es habitual que las cadenas de televisión programen atractivos documentales en los que se narra la realización de algún éxito reciente. Se trata de los ya populares making off [sic]".

Multiplex: complejo que alberga varias salas cinematográficas. El uso de esta acepción data, según el Merriam-Webster, de 1985. Esta fecha coincide con el auge del mercado del vídeo que, según El Cine $(2002$, p. 66) se produjo a comienzos de los 80 y propició que se emprendieran "reformas para convertir el cine señorial en un conjunto de pequeñas y modernas multisalas. [...] donde antes solo se programaba una película, ahora el espectador podía elegir entre tres, cuatro o cinco". 
Showbusiness: negocio o industria del espectáculo. En el Merriam-Webster se establece la fecha de aparición en 1850. M. Görlach (ibídem) la determina para el español en la década de los 70. El DLE la incluye por primera vez en su última edición como lexía compuesta (show business), a la par que suprime el sustantivo del que deriva (show).

Star-system: forma de organización de la producción cinematográfica, basada en la popularidad de los actores. En español se empieza a usar en la década de 1970 (Görlach, 2001:304), mientras que en inglés, su empleo se remonta a 1832 (MerriamWebster). En El Cine (2002, p. 20) se explica el origen de este uso: "los responsables de los estudios observaron que con quien verdaderamente soñaban los espectadores era con los actores de películas [...]. Eran precisamente los actores quienes, en la mayoría de las ocasiones, atraían al público a las salas. Entonces, el director empezó a perder importancia a favor del actor, que era la estrella, el ídolo. Comenzó de esta forma a construirse lo que se conocería con el nombre de starsystem; es decir, una producción cinematográfica hecha a la medida de las estrellas". De la difusión de este concepto en nuestra cultura dan cuenta las irónicas palabras del célebre periodista Carlos Alsina acerca de la aparición de Pablo Iglesias, Secretario General de Podemos, en la Gala de los Goya de 2016: "Ahora que ya formaba parte del sistema, a Podemos le faltaba formar parte del star system. Y ahí está Pablo, feliz de codearse por fin con un montón de famosos que, en muchos casos, son peores actores que él. Y sin haber pasado él por la escuela de arte dramático" (Alsina, 2016)

Teenexploitation: género cinematográfico dirigido a los adolescentes. Como paradigma de anglicismo del cine relacionado con su explotación comercial, El Cine (2002, p. 70) establece una clara relación entre este género y la industria de Hollywood: "La ansiedad por obtener dinero fue la nota dominante en el cine norteamericano de la década de 1990 [...] Como los estudios indicaban que la gente joven era mayoritariamente la que acudía a las salas, se pusieron en marcha multitud de títulos dedicados especialmente a ellos. Las películas ambientadas en institutos y universidades americanas, que ya habían tenido éxito en la década anterior, se convirtieron ahora en un auténtico género, el denominado «cine teen», que obtenía unas recaudaciones más que notables".

Underground: T. Guzmán (2003, glosarios combinados), citando la Enciclopedia Británica, da una definición específica del lenguaje cinematográfico: "película realizada y distribuida fuera de la industria fílmica comercial" y añade que el término se extendió en la década de 1950, cuando los materiales fílmicos empezaron a estar al alcance de los legos, lo que permitió que estos se interesaran por el arte 
cinematográfico. No obstante, según M. Görlach (2001, p. 338), que se sorprende de lo arraigado que está este anglicismo en muchas lenguas europeas en detrimento de los términos nativos, en español no se emplea hasta una década posterior.

\subsection{Anglicismos referidos a tendencias o movimientos cinematográficos}

Blaxploitation: explotación de actores negros por parte de los productores de películas sobre negros. El Merriam-Webster data su acuñación en 1972. Se trata de un movimiento cinematográfico que tuvo lugar en Estados Unidos a principios de los 70 con la comunidad afroamericana como protagonista principal, y no solo en papeles de esclavos o criados (Guzmán, 2003, glosario 1999-2001). Ciertamente, antes de esta década, el cine ya había mostrado una tendencia al cambio en este sentido con Adivina quién viene a cenar esta noche - Guess who's coming to dinner? de Stanley Kramer en 1967, pero es en este momento cuando el cine comienza a dar voz a la población negra. El fenómeno constituyó tal éxito que William Crain llegó a dirigir una película sobre un vampiro negro llamado Blácula, en 1972; William A. Levey realizó Blackenstein en 1973; y Lee Frost, The Black Gestapo, en 1975.

Brat Pack: apodo que, irónicamente (brat significa mocoso), se aplica a un grupo abierto de actores que solían aparecer juntos en películas de adolescentes en la década de los 80. Brat Pack es un juego de palabras que recuerda al Rat Pack, encabezado por Frank Sinatra entre los años 50 y 60. Según se lee en la Enciclopedia Universal Multimedia Micronet, la película Rebeldes, de Francis Ford Coppola, "se convirtió en una plataforma induscutible para un grupo de jóvenes desconocidos y anticipó los rostros de algunas futuras estrellas sobre las que se sostuvo el Hollywood de las dos décadas siguientes. Se conoció a este grupo como "brat pack" o "pandilla de mocosos" y se incluyeron en él nombres como los de Tom Cruise, Matt Dillon, Patrick Swayze o Ralph Macchio, entre otros".

Free Cinema: movimiento cinematográfico británico que exalta la libertad del individuo y el significado profundo de las realidades cotidianas. En El Cine (2002, p. 49) se explica en qué consiste el movimiento: “El cine británico también tuvo su propio revulsivo en la década de 1960. Precedido por la obra de Jack Ckayton Un lugar en la cumbre, bajo el nombre de 'free cinema' se formó un movimiento que pretendía dotar de aire fresco a la anquilosada industria británica, interesado por llevar las cámaras a los barrios industriales para denunciar las barreras sociales y la miseria que existía en el interior del país".

Rat Pack: T. Guzmán lo define como el grupo de artistas y amigos, de entre los cuales los más conocidos eran Frank Sinatra, Sammy Davis Jr. y Dean Martin. La Enciclopedia Universal Multimedia Micronet, por su parte, dice que el rat pack fue un 
"grupo de amigos que dominó la escena musical americana a principios de los 60". A pesar de que en la definición que aporta la enciclopedia solo se hace referencia a la actividad musical de esta pandilla de ratas, lo cierto es que se dedicaban al mundo del espectáculo en general y, como explica T. Guzmán (2003: glosario 1999-2001), a ella también pertenecían actores.

\section{Conclusiones}

Lo primero que se observa al analizar los anglicismos recogidos en este estudio es que constituyen casos de préstamos culturales, de acuerdo con la terminología de L. Bloomfield. Se trata de extranjerismos que se emplean para designar una novedad foránea, que se ha importado también en la cultura receptora. Sin embargo, dentro del ámbito y las culturas que nos ocupan, estos trasvases son prácticamente unidireccionales: se dan desde la cultura anglosajona, principalmente estadounidense, a la española. En este sentido, podríamos calificarlos también de préstamos íntimos. Por razones de espacio, hemos obviado las implicaciones lingüísticas que el uso de estos anglicismos en español conlleva, para centrarnos en su impacto cultural.

Entre los 68 anglicismos registrados se dan diferencias notables respecto al grado de penetración en la cultura española: existen algunos que podrían considerarse xenismos porque remiten a una realidad extranjera que se percibe como tal. Ejemplos de ello serían Far West, Rat Pack o Razzie, por mencionar solo algunos casos de distintas categorías. Dentro de estos, se da un fenómeno curioso en lexías, como eurowestern o spaghetti western, que claramente pretenden imitar ese rasgo cultural estadounidense.

Hemos encontrado también algunos casos de anglicismos, como zombie o cartoon, que, habiendo nacido en otras cinematografías u otras lenguas, deben a Estados Unidos su difusión e incluso el término que las designa. Otro grupo relacionado con este son las lexías que han experimentado extensiones semánticas dentro del inglés gracias al ámbito fílmico. Slapstick, Major o Outlaw no son palabras específicas del cine, pero se usan en él para aludir a una realidad cultural específica. Igualmente, un término como freak, que nació en inglés común con el significado de extraño, pasó a designar, al menos en español, a un tipo de personaje de las películas de terror y últimamente, probablemente también gracias a la influencia del cine y de la televisión, a un personaje inofensivo y extravagante, obsesionado con algo.

Anglicismos como sheriff, gangster o it girl se emplean, a veces incluso en el lenguaje común, aplicados a personajes locales que cumplen ciertas características, sin que necesariamente se esté aludiendo al tipo anglosajón. Estos serían los casos más 
llamativos de impacto cultural puesto que se han filtrado de tal manera en la cultura meta que se ha difuminado su asociación con el mundo de Hollywood. Sin haber perdido esta connotación, hay otro grupo de anglicismos del cine que ha generado analogías o costumbres entre los españoles, por ejemplo cuando se hace referencia al star system para designar al elenco de actores y actrices españoles famosos o el hábito de emplear frases extraídas de películas de Hollywood míticas, como "siempre nos quedará París" o "que la fuerza te acompañe" en las despedidas. Asimismo, no deja de ser llamativa la popularidad de que gozan en España las aventuras tipo Route 66 o la reciente transformación de las ceremonias de graduación en institutos y universidades españolas, por una incuestionable influencia de las road movies y las teen movies respectivamente.

Por último, cabe mencionar que, dentro del grupo de anglicismos relacionados con la industria cinematográfica, muchos de ellos reflejan un rasgo cultural propio del cine hollywoodiense que se ha exportado, en mayor o menor medida, a las cinematografías del resto del mundo: se trata del empleo del marketing aplicado al cine para multiplicar los beneficios económicos. Así, estrategias como la inclusión en el DVD del Director's cut o del making of en la fase de difusión posterior al estreno de las películas, ya consiste en una práctica habitual generalizada.

\section{Article history}

Paper received: 22 March 2017

Paper received in revised form and accepted for publication: 29 June 2017

\section{About the Author}

Dr. Goretti García Morales has been lecturing and researching at Universidad de Las Palmas de Gran Canaria since 2003. She has mainly focused on two investigation fields. One of them is the influence of loanwords from English into Spanish. Her PhD dealt with Anglicisms in Spanish film reviews and there are several papers signed by her on this and other related topics. She is also interested in the historiography of languages interpretation, especially in the role played by interpreters during the Spanish Inquisition, as her national and international publications show. Dr. García Morales has also participated in 
numerous research and innovative education projects with the Anglosaxon language and culture at their heart.

\section{Referencias}

Alfaro, Ricardo J. (1948). El anglicismo en el español contemporáneo. Boletín del Instituto Caro y Cuervo, 4, 102-128.

Alsina, Carlos. (2016). ¿Quién es el títere y quién el titiritero? Disponible en http://www.ondacero.es/programas/mas-de-uno/audios-podcast/monologo-dealsina/monologo-de-alsina-esta-claro-que-a-pablo-iglesias-le-queda-mejor-la-camisade-alcampo-que-el-esmoquin_2016020856b83fc74beb28fff7cd30da.html [22/01/2017]

Baker, Lindsay. (2001). Got it? Disponible en https://www.theguardian.com/lifeandstyle/ 2001/apr/21/weekend.lindsaybaker1 [09/05/2017]

Borau Moradell, José Luis. (2008). El cine en nuestro lenguaje. Discurso de aceptación en la Real Academia Española de la Lengua. Disponible en http://www.rae.es/academicos/ jose-luis-borau-moradell [10/01/2017]

Bradley, Wini \& Carrera de la Red, Fátima. (2004). Un estudio comparativo de los anglicismos correspondientes a los ámbitos del cine y de la música. Actas del $\mathrm{V}$ Congreso de Lingüística General. León 5-8 marzo 2002, 459-464.

Collins English Dictionary. (1991). Glasgow: Harper Collins.

Dirigido por..., Barcelona, Dirigido Por, S.L., № 339, noviembre 2004.

El Cine [V. MÉRIDA DE SAN ROMÁN, PABLO]

Enciclopedia Universal Multimedia Micronet. (2004). Madrid: Micronet.

García Morales, Goretti. (2009). Análisis de los anglicismos léxicos del lenguaje cinematográfico registrados en muestras escritas entre 2002 y 2006. Tesis doctoral. Las Palmas de Gran Canaria: Universidad de Las Palmas de Gran Canaria. Disponible en http://hdl.handle.net/10553/3585 [10/01/2017]

García Morales, Goretti. (2016). A Study of Loanwords from English in Spanish Film Reviews. En F. Alonso Almeida, I. Ortega Barrera, E. Quintana Toledo, M. Sánchez Cuervo (Eds.), Input a Word, Analyze the World (pp.359-378). Newcastle: Cambridge Scholars Publishing.

Gómez Capuz, Juan. (1998). El préstamo lingüístico: conceptos, problemas y métodos. Valencia: Departamento de Filología Española: Universitat de València.

Gómez Capuz, Juan. (2001). La interferencia pragmática del inglés sobre el español en 
doblajes, telecomedias y lenguaje coloquial: una aportación al estudio del cambio lingüístico en curso. Tonos Digital, Revista electrónica de Estudios Filológicos. Disponible en www.um.es/tonosdigital/znum2/estudios/Doblaje.htm. [07/02/2017]

Gómez Capuz, Juan. (2004). Préstamos del español: lengua y sociedad. Madrid: Arco Libros.

Gómez Capuz, Juan. (2005). La inmigración léxica. Madrid: Arco Libros.

Görlach, Manfred. (2001). A Dictionary of European Anglicisms. Oxford: Oxford University Press.

Guzmán González, Trinidad. (1986). Algunos aspectos de los anglicismos cinematográficos. Razones de su empleo. En actas del IX Congreso Nacional, Murcia, 17-20 de diciembre de 1985. Aspectos comparativos en la lengua y literatura de habla inglesa (pp. 175-184). Murcia: Servicio de publicaciones de la universidad de Murcia.

Guzmán González, Trinidad (2003). The impact of lexical Anglicisms in Spanish Film Magazines: a case study across time. Historical Sociolinguistics and sociohistorical linguistics. University of Leiden, Leiden. Disponible en http://www.let.leidenuniv.nl/ hsl shl/anglicisms.htm [31/01/2017]

Lázaro Carreter, Fernando. (1997). El dardo en la palabra. Barcelona: Galaxia Gutenberg Círculo de Lectores.

Lázaro Carreter, Fernando. (2003). El nuevo dardo en la palabra. Madrid: Aguilar.

Lorenzo Criado, Emilio. (1996). Anglicismos hispánicos. Madrid: Gredos.

Luján-García, Carmen. (2012). Anglicismos en el español actual: un estudio de la prensa escrita cinematográfica. Español actual, revista de español vivo 97, 67-88.

Mérida de San Román, Pablo. (2002). El Cine: Historia del cine. Técnicas y procesos. Actores y directores. Diccionario de términos. 100 grandes películas. Barcelona: Spes.

Merriam-Webster Inc. Dictionary and Thesaurus Online. Disponible en http://www.merriam-webster.com/. [06/03/2017]

Moliner, María. (2007). Diccionario de Uso del Español (3 ed.). Madrid: Gredos.

Nosferatu, San Sebastián: Donostia Kultura, № 41-42, octubre 2002.

N ${ }^{\circ} 51$, marzo 2006.

Ortega Arjonilla, Emilio. (2011). El francés de las humanidades y su traducción al español: calcos, préstamos, xenismos y adaptaciones. Anales de Filología Francesa, 19, 235-253.

Pratt, Chris. (1980). El Anglicismo en el español peninsular contemporáneo. Madrid: Gredos.

Real Academia Española. (2005). Diccionario Panhispánico de Dudas. Madrid: Real Academia Española.

Real Academia Española. (2014). Diccionario de la Lengua Española. Madrid: Real 
Academia Española.

Riquelme Pomares, Jesucristo. (1998). Anglismos y anglicismos: huéspedes de la lengua. Alicante: Ayuntamiento de Torrevieja.

Rodríguez González, Félix y Lillo Buades, Antonio. (1997). Nuevo Diccionario de Anglicismos. Madrid: Gredos. 